Journal of Bangladesh Academy of Sciences, Vol. 39, No. 1, 83-90, 2015

\title{
MANAGEMENT OF ANTHRACNOSE AND BLIGHT DISEASES OF HOUTTUYNIA CORDATA THUNB. WITH FUNGICIDES
}

\author{
SHAMIM SHAMSI* AND TRISHA SAHA \\ Department of Botany, University of Dhaka, Dhaka-1000, Bangladesh
}

\begin{abstract}
Two types of symptoms, namely anthracnose and blight were recorded on Houttuynia cordata Thunb. during the period of April to December 2013. The isolated fungi from the diseased plants were Alterneria alternata (Fr.) Keissler and Colletotrichum gloeosporioides (Penz.) Sacc. Five fungicides viz., Bavistin DF, Dithane M-45, Indofil, Salcox 50 WP and Tall 25 EC were evaluated against the pathogenic fungi at 100, 200, 300, 400 and 500 ppm concentrations. Tall 25 EC was found most efficient inhibitor of the test fungi followed by Bavistin, Indofil, Dithane M-45 and Salcox. In vivo treatment Tall $25 \mathrm{EC}$ was found most effective in controlling the diseases.
\end{abstract}

Key words: Anthracnose, Blight, Houttuynia cordata, Management, Fungicides

\section{INTRODUCTION}

The plant Houttuynia cordata Thunb. is a traditional medicinal herb. The species belongs to the family Saururaceae. It is known as "Chameleon Plant" and its local name is "Aistya Gachh". This plant is mainly native to Japan, Korea, Southern China and southeast Asia. It is widely distributed in the tropical Himalaya from Garwhal to Sikkim, Assam, Khasia Mountains. It mostly grows in hilly areas in moist and shady places. In Bangladesh, it is found in Sylhet and Narail districts (Ahmed et al. 2009).

Its ethnobotanical uses considered for poisoned sores (furuncles), infectious skin diseases, piles, malaria, snakebite and other ailments. It is used as an antipyretic and detoxicant and is frequently used to treat pulmonary infections (Smith and Stuart 1973). It is antitumorous and is a special medicine for lung cancer (Wang 1994, Zhu 1998). A decoction is used internally in the treatment of many ailments including cancer, coughs, dysentery and fever. It is said that it helps to strengthen the immune system. The leaf juice is antitode and astringent. A root extract is diuretic. The root is also said to be used in medicinal preparations for certain diseases of women. The rhizomes yield a sterol, which stimulates the secretion of antibiotic substances from a Gram-positive sporeforming bacillus (Dong et al. 1998).

Considerable research has been done on ethnobotanical and medicinal properties of the plant abroad. But a few information is available regarding the fungal diseases of the

\footnotetext{
* Corresponding author : <prof.shamsi@gmail.com>.
} 
plant home and abroad (Azad and Shamsi 2011, Zheng et al. 2011). Zheng et al. (2011) also reported that symptoms appeared on leaves of $H$. cordata from September 2007 to November 2009 in Dangyang County, Hubei, China. He also reported the crop area affected estimated to be over 600 ha per year. Rhizome yield was reduced by $20 \%$ on average, with up to $70 \%$ yield losses in some fields during the autumn growing season.

In Bangladesh, Azad and Shamsi (2011) worked on H. cordata and reported 17 species of fungi associated with the plant. So far, there is no report available regarding the control of the diseases caused by $H$. cordata. Present attempt was made to find out suitable control measures of the plant.

\section{MATERIALS AND METHODS}

The leaves of $H$. cordata showing anthracnose and blight symptoms were collected from experimental field of Botanical Garden, Curzon Hall campus, Dhaka University, during the period of April, 2013 to December, 2013. The associated fungi were isolated from the samples following the "Tissue Planting" and "Blotter" method on PDA medium (CAB 1968).

Identification of the isolates was determined following the standard literatures (Barnrett and Hunter 2000, Ellis 1971, 1976; Ellis and Ellis 1997, Sutton 1982).

All the isolated fungi were tested for their pathogenic potentiality following "Detached leaf technique" (Azad and Shamsi 2011).

The pathogenic fungi screened from "Detached leaf assay" were selected for net house experiment. Healthy plants of $H$. cordata were grown on 12 inch (diam.) earthen pot containing sterilized soil for 6 weeks. The overall experiment was conducted in net house. Five plants were transplanted in each pot. Three replications were made for each treatment. Five pots were provided for each replication. Test fungi were grown on PDA medium for $7-10$ days. Spore suspension of each pathogenic fungus at the rate of $10^{4}$ concentrations was sprayed on healthy plants using hand sprayer. Inoculated plants were covered by perforated polythene bags to avoid contamination and to maintain humidity. Symptoms were recorded and fungi were re-isolated to fulfill Koch's postulate.

Five fungicides with different active ingredients, viz., bavistin $50 \mathrm{WP}$, dithane M-45, indofil, salcox $50 \mathrm{WP}$ and Tall $25 \mathrm{EC}$ were collected from the Krishi Upokoron Biponi Kendro, Khamarbari, Farmgate, Dhaka. These fungicides at 100, 200, 300, 400 and 500 ppm concentrations were evaluated against the fungi.

For each fungicide, a stock solution having the concentration of $10,000 \mathrm{ppm}$ was prepared. The calculated amount of the stock solution of a fungicide was supplemented with sterilized PDA medium to get the above mentioned concentrations. 
The concentrations of fungicides are expressed in terms of its active ingredients. Twenty $\mathrm{ml}$ of the supplemented medium of a particular concentration was poured in a sterilized Petri plate and allowed to solidify. In the control set, required amount of sterile water instead of fungicide solution was added to the PDA medium. Five mm mycelial agar disc cut from the margin of actively growing culture of test fungi for each treatment was placed at the center of the plate. Three replications were maintained in each case. The inoculated plates were incubated at $25 \pm 2{ }^{\circ} \mathrm{C}$. The radial growth the colonies was measured at the 5 th day of inoculation.

The fungitoxicity in terms of percentage inhibition of mycelial growth was calculated using the formula:

Per cent inhibition $=\frac{C-T}{C} \times 100$

where $\mathrm{C}=$ Average increase in mycelial growth in control plate and $\mathrm{T}=$ Average increase in mycelial growth in treatment plate.

Among the five fungicides used in controlling in vitro growth of test fungi, Tall 25 EC showed the best result. Thus this fungicide was selected for in vivo test for controlling the test fungi in the net house at lowest concentration $100 \mathrm{ppm}$. Five plants were transplanted on each pot containing sterilized soil and allowed to grow for 6 weeks. Three replications were maintained for the experiment. Five pots were maintained for each replication. Suspension of Tall $25 \mathrm{EC}$ at $100 \mathrm{ppm}$ concentration was sprayed on healthy plants by hand sprayer. This suspension was made following the same way as it was made in the laboratory for in vitro test. Control plants were sprayed with distilled water. Then all the plants were covered by perforated polythene bag for 48 hours to slow the rate of evaporation of fungicide from plat surface. These pots were observed for one month for disease appearance under natural condition.

The experiment was conducted in net house of Botanical garden, Curzon Hall, Campus, DU.

\section{RESULTS AND DISCUSSION}

A total of 7 species of fungi were isolated from 18 diseased samples of $H$. cordata. These 7 species belonged to 6 genera. The isolated fungi were Alterneria alternata, Aspergillus fumigatus, Aspergillus niger, Colletotrichum gloeosporioides, Curvularia lunata, Pestaliopsis guepinii and Rhizopus stolonifer. Present result slightly differed from Azad and Shamsi (2011) who reported 17 species of fungi that were associated with $H$. cordata. 

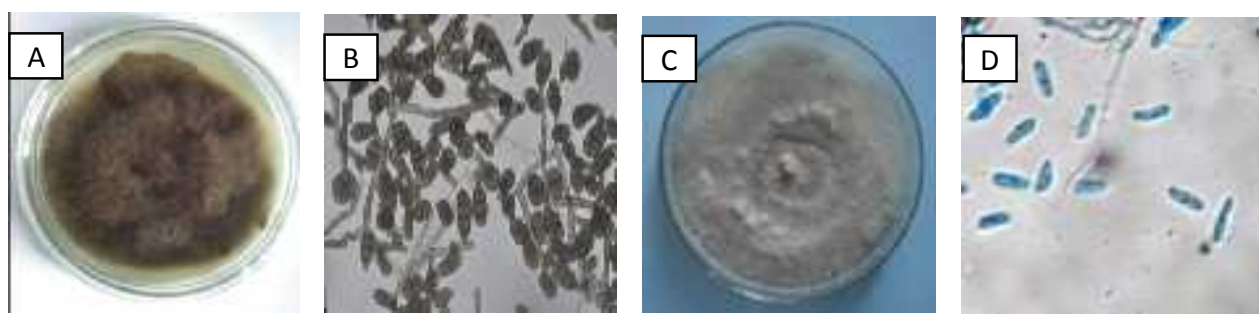

Plate 1. A-B: Culture plate, conidiophores and conidia of Alterneria alternata; C-D : Culture plate, conidiophores and conidia of Colletotrichum gloeosporioides $(\mathrm{Bar}=50 \mu \mathrm{m})$.
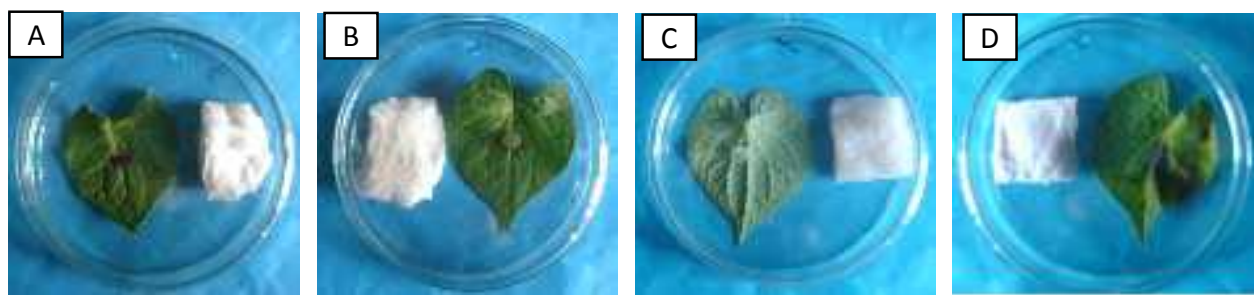

Plate 2. Houttuynia cordata: A. Uninoculated dorsally pricked leaf of. B. Uninoculated ventrally pricked leaf. C. Symptom produced by Colletotrichum gloeosporioides on dorsally inoculated leaf. D. Symptom produced by Alterneria alternata on dorsally inoculated leaf.
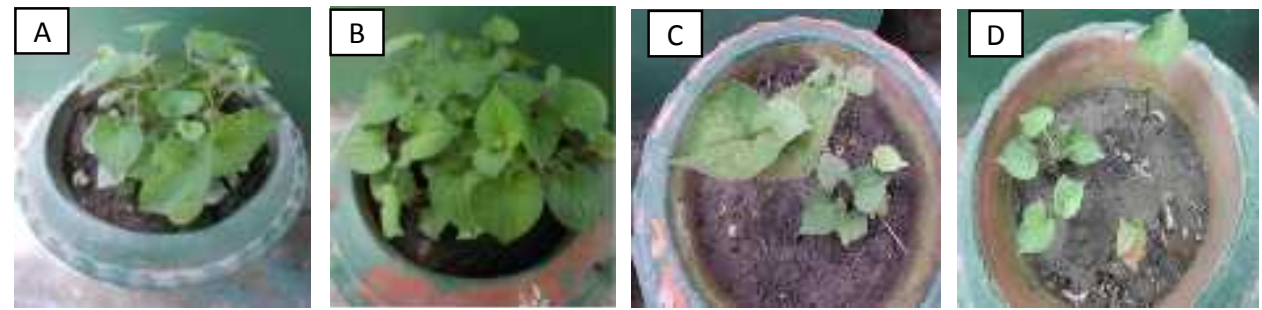

Plate 3. Houttuynia cordata: A-B Control plant; C. Symptom caused by artificial inoculation of Alterneria alternata; D. Symptom caused by artificial inoculation of Colletotrichum gloeosporioides.
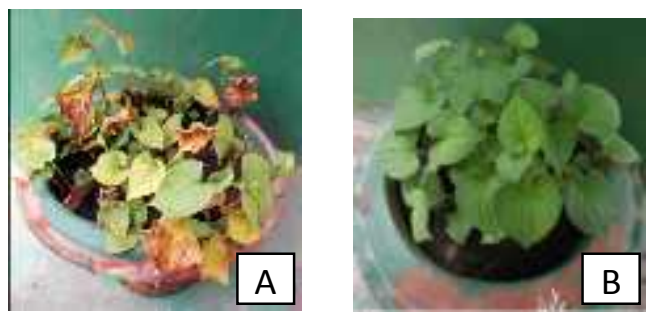

Plate 4. Houttuynia cordata: A. Infected plants (Control). B. Plants treated with Tall EC at $100 \mathrm{ppm}$ concentration.

The seven fungal species isolated from the plant in the present study were tested for their pathogenecity potentiality. The pathogenecity test following "detached leaf inoculation assay" revealed that $A$. alternata and $C$. gloeosporioides produced symptoms 
on $H$. cordata. Zheng et al. (2011) first reported leaf spot of $H$. cordata caused by $A$. alternata from China.

Azad and Shamsi (2011) recorded two types of symptoms (Anthracnose and leaf spot) on $H$. cordata and 17 species of fungi were associated with symptoms in their experiment. Among these fungi they found 3 species of Colletotrichum pathogenic to the plant. Result of present study slightly differed from previous result of Azad and Shamsi (2011).

Anthracnose and blight were the symptom recorded in present study. Colltotrichum gloeosporioides and A. alterenata were the fungi that were found pathogenic to this plant. After seven days of inoculation it was noticed that two test fungi A. alternata and $C$. gloeosporioides are capable of infecting plants. Control plants remained symptomless. All the treated plants showed anthracnose and blight symptoms. Test fungi were isolated from inoculated plants successfully (Plates 2, 3).

Taxonomic enumeration of the pathogenic fungi: Alternaria alternata (Fr.) Keissler Colony usually black or olivaceous black, sometimes grey. Conidiophores arising singly or in small groups, simple or branched, straight or flexuous, sometimes geniculate, pale to mid olivaceous or golden brown, smooth, up to 50 um long. 3 - 6 um thick with 1 or several condial scars. Conidia formed in ling, often branched chains, obclavate, obpyriform, ovoid or eelipsoidal, often with a short conidial or cylindrical beak, pale to mid golden brown, smooth or verruculose, with up to 8 transverse and usually several longitudinal or oblique septa, overall length 20 - 63 (37) um, 9 - 18 (13) um thick in the broadest part, beak pale, 2 - 5 um thick. (Plates 1. A-B)

Colletotrichum gloeosporioides (Penz.) Sacc. Colonies are variable; sclerotia occasionally present. Conidia are straight, obtuse at the apex, (6.2) 11-20 to 2.2-3.4 (5) um. Appressoria are 8.4-11.2 to 4.2-8.0 um, clavate or irregular, sometimes becoming complex. (Plate 1. C-D)

Fungitoxicity of fungicides against radial growth of Alterneria alternata in vitro: Bavistin DF, Dithan M-45, Indofil and Tall 25 EC completely inhibited the radial growth of the test fungus at 500 and 400 ppm concentrations. Salcox 50 WP completely inhibited the radial growth of fungus exclusively at $500 \mathrm{ppm}$ concentration. Bavistin DF inhibited $76.47,70.50$ and $58.82 \%$ radial growth of the fungus at 300, 200 and $100 \mathrm{ppm}$ concentrations. Diathane M-45 showed 85.8\%, 76.47 and $72.95 \%$ inhibition of radial of growth of the fungus at the same concentrations. 


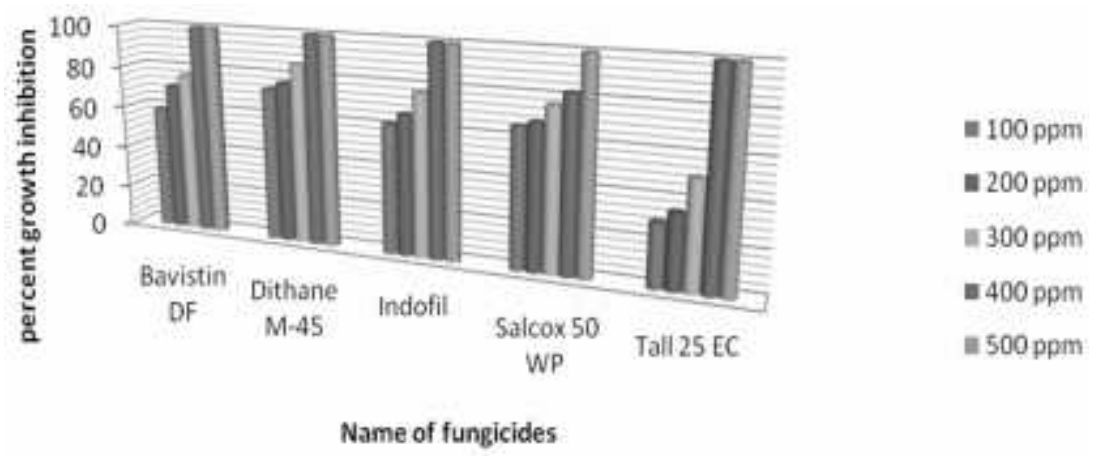

Fig. 1. Fungitoxicity of fungicides against the radial growth of Alterneria alternata at different concentrations.

Indofil showed $77.19,66.76$ and $61.40 \%$ inhibition of radial growth of the fungus at 300, 200 and 100 ppm concentrations. Salcox inhibited 82.35, 76.47, 68.23 and 65.88\% radial growth of the fungus at 400,300, 200 and $100 \mathrm{ppm}$ concentrations, respectively. Tall 25 EC inhibited 50.88, 35.09 and $29.82 \%$ radial growth of the fungus at 300, 200 and 100 ppm concentrations (Fig. 1).

Fungitoxicity of fungicides against radial growth of Colletotrichum gloeosporioides in vitro: Bavistin, indofil and Tall $25 \mathrm{EC}$ showed complete inhibition of radial growth of test fungus at all the concentration used. Dithane M-45 showed complete inhibition of radial growth of fungus at $500 \mathrm{ppm}, 400 \mathrm{ppm}$ and $300 \mathrm{ppm}$ concentrations. The same fungicide at $200 \mathrm{ppm}$ and $100 \mathrm{ppm}$ concentrations showed $68.85 \%$ and $57.08 \%$ inhibition of radial growth of the test fungus. Whereas Salcox showed complete inhibition of radial growth of the fungus exclusively at $500 \mathrm{ppm}$ concentration as observed in case of A. alternata. At $400 \mathrm{ppm}, 300$ ppm, 200 ppm and 100 ppm concentration it showed 81.18\%, 70.35\%, 55.30\% and 47.06\% inhibition of radial growth of test fungus. This observation is very near to effect of the fungicidal action of Salcox as observed in case of A. alternata (Fig. 2).

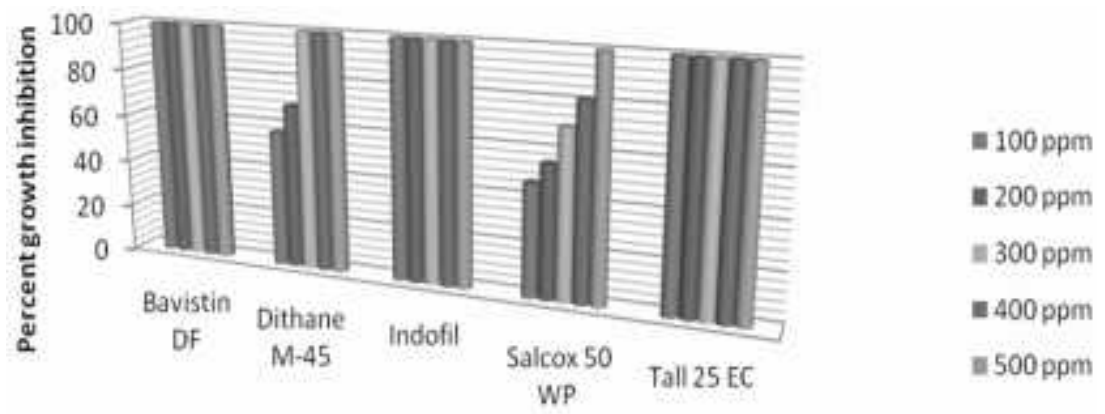

\section{Name of fungicides}

Fig. 2. Fungitoxicity of fungicides against the radial growth of Colletotrichum gloeosporioides at different concentrations. 
Effects of fungitoxicity in controlling diseases of Houttuynia cordata: Selected fungicide Tall $25 \mathrm{EC}$ at $100 \mathrm{ppm}$ concentration was sprayed over the plants in net house. After 15 days of application of fungicide the treated plants showed no infection. Moreover, plants treated with fungicides showed luxuriant growth as well as plant height and leaf size also increased. On the other hand control plants gradually become infected by the fungi showing symptoms. Plants become shorter compared to treated plants. Up to one month of observation, treated plants remained symptomless (Table 1, Plate 4)).

Table 1. Effects of Tall $25 \mathrm{EC}$ on plant height and leaf size of $\boldsymbol{H}$. cordata.

\begin{tabular}{|c|c|c|c|c|c|}
\hline \multicolumn{3}{|c|}{ Control plants } & \multicolumn{3}{|c|}{ Tall 25 EC treated plants } \\
\hline Plant height & Leaf length & width $(\mathrm{cm})$ & Plant height & Leaf length & width $(\mathrm{cm})$ \\
\hline 18.0 & 4.4 & 3.3 & 23.0 & 5.5 & 4.3 \\
\hline
\end{tabular}

Mean calculated from 25 plants examined

\section{ACKNOWLEDGEMENTS}

The authors feel proud it a privilege to express gratitude to Chairman Dr. Moniruzzaman Khandker and Ex-Chairman Dr. Abdul Aziz, Department of Botany, University of Dhaka, for providing laboratory facilities for carrying out the present work. The authors are also expressing their gratefulness to Professor Abul Bashar, Department of Botany, University of Dhaka, for his constant direction, inspiration and cooperation during the course of the study. The authors express their gratitude and thanks to "Ministry of Science and technology" for the financial support in the form of NST fellowship to the first author as M.S. Scholarship.

\section{REFERENCES}

Ahmed, Z.U., M.A. Hassan, Z. N. T. Begum, M. Khondker, S. M. H. Kabir, M. Ahmed and A. T. A. Ahmed (eds.) 2009. Encyclopedeia of Flora and Fauna of Bangladesh, Vol.10. Angiosperm: Dicotyledons (Ranunculaceae- Zygophyllaceae). Asiatic Society of Bangladesh, Dhaka. pp. 227.

Azad, R. and S. Shamsi. 2011. Identification and pathogenic potentiality of fungi associated with Huttuyania cordata Thunb. Dhaka Univ. J. Biol. Sci. 20(2): 131-138.

Barnett, H. L. and B. B. Hunter. 2000. Illustrated Genera of Imperfect Fungi. (4th edn.), Burgessbub. Co. Minneapolis. pp.218.

CAB (Commonwealth Agricultural Bureau) 1968. Plant Pathologist's Pocket Book. The Commonwealth Mycological Institute. Kew. Surrey. England. pp. 267.

Dong, K.S., X. Q. Wang., and Y. F. Dong. 1998. Xian Dai Lin Chuang Zhong Yao Xue [Contemporary Clinical Chinese Materia Medioca]. Beijing: Zhong Guo Zhong Yi Yao Press.

Ellis, M. B. 1971. Dematiaceous hyphomycetes. The Commonwealth Mycological Institute, England, pp. 608. 
Ellis, M. B. 1976. More Dematiaceous hyphomycetes. The Commonwealth Mycological Institute, England, pp. 507.

Ellis, M. B. and J. P. Ellis. 1997. Micro fungi on Landplants. An Identification Handbook. pp. 868.

Smith, F.P. and G.A.Stuart, (1973). Chinese Medicinal Herbs. San Francisco: Georgetown Press.

Sutton, B.C. 1980. The Coelomycetes, Fungi Imperfecti with Pycnidia Acervuli and Stromata. Commonwealth. Mycological Institute. England. pp. 525-537.

Wang, J. H. (Ed.) 1994. Xin Bian Chang Young Zhong Yao shou Ce [Manual of Commonly Used Chinese Medicinal Herbs]. Beijing: Jin Dun Press.

Zhu, Y. 1998. Chinese Materia Medica-Chemistry, Pharmacology and Applications. Amsterdam: Harwood Academic Publishers.

Zheng, L., R. Lv, Q. Li, and J. Huang. 2011. First Report of Leaf Spot of Houttuynia cordata caused by Alternaria alternata in China. Plant disease.APS Journal. 95(3): 358

(Received revised manuscript on 31 March, 2015) 